\title{
Study on the Influence of the Classical Aesthetics Proposition on Chinese Early Painting Concepts
}

\author{
Jiachuan $\mathrm{Lu}$ \\ School of Social Development \\ Nanjing Normal University \\ Nanjing, China 210046 \\ School of Art and Design \\ Zhongyuan University of Technology \\ Zhengzhou, China 450007
}

\begin{abstract}
Proposition is a kind of value theory, which is the value rule formed by the life subject of things. As a theoretical form under the influence of certain concepts, it is embodied in the general nature and operation law of things. The early Chinese ancient paintings evolved under the internal and external guidance of the aesthetic proposition. In a certain period, certain aesthetic thoughts and conceptual appeals were embodied. In essence, as the value of navigation in the art process, the general nature and value law revealed by the aesthetic proposition are not only the aesthetic justice and the human consensus in the social thoughts, but also the sublimation and enlightenment of the aesthetic consciousness in artistic creation.
\end{abstract}

Keywords-ancient China; aesthetic proposition; early painting; unity of heaven and man

\section{INTRODUCTION}

The aesthetic proposition is a kind of condensation of value, a kind of positioning and guidance of the law of operation and the speculation of ideas. It is also the general view and viewpoint of the life attributes of the universe generated by a certain era. In the early Chinese ancient paintings, the aesthetic proposition constituted the value trend and life attribute of art, and embodied the ontological definition of art and the social aesthetic consensus in a certain aesthetic direction.

In essence, Chinese painting art is a conceptual carrier based on the interaction between man and nature, man and universe, and man and heart. All the laws of creation are also the general aesthetic cognition of society. Artistic thought is philosophy and aesthetics thought, which is a more succinct, more complete experience and thinking that is generated in response to the spiritual world of man. From the early ancient Chinese characters such as paintings, tomb murals, portrait stones, and portrait bricks, the categories of "Heaven and Man", "Shaping and God", and "Italian and Image" in aesthetics also constitute the aesthetic thinking in concept of painting. The painting creation is to communicate the relationship between man and God, man and heaven, and man and nature through a certain visual image, leading the human heart to be completed from consciousness.

\section{THE VIEW OF "UNITY OF HEAVEN AND MAN" AND} THE VALUE DESTINATION OF ANCIENT EARLY PAINTINGS

"Unity of Heaven and Man" is one of the fundamental propositions of Chinese classical philosophy and classical aesthetics, as well as the origin of ancient Chinese painting art. This aesthetic concept with simple dialectic brings together the great wisdom of the ancients and opens up the highest ideals in the Chinese spiritual world and the highest law of life. "Unity of heaven and man" includes two meanings, one is that "the heaven and men are in a same body" That is, the universe is the representation of heaven while the human heart is the source of heaven, and the two are united. The second is "the connection between heaven and man." That is, people and nature can mutually interact and connect. "

As for the relationship between heaven and man, "Zhuangzi" advocates 'unity of heaven and man'. The fundamental point of his thought of "unity of heaven and man" is that people's spirit and natural spirit namely 'Tao', can be unified. Therefore, he advocates that the highest realm of human spiritual life is to be united with heaven and earth, and 'exchange with the spirit of heaven and earth'." ${ }^{2}$ Dong Zhongshu of the Western Han Dynasty further developed these views and pointed out that "heaven also has the mood of anger and joy, and the heart of sorrow and happy, which is like human. In a similar fashion, the heavens and the people are also united", and the heavens and the earth are one unity." ${ }^{3}$ For the first time, he completed the interpretation of the value proposition of "unity of heaven and man".

As an important aesthetic proposition, "unity of heaven and man" has been quoted by various disciplines throughout history. In different contexts, there are many explanations.

\footnotetext{
Hao Yong, "The Gene of Chinese Culture: Confucianism and Taoism", Guangming Daily Press, 2009, p. 83.

Dong Zhongshu, Zeng Zhenyu, "Chun Qiu Fan Lu, Yin and Yang Yi", Henan University Press, 2009, p. 297.

Dong Zhongshu, Zeng Zhenyu notes, "Chun Qiu Fan Lu, Deep Inspection", Henan University Press, 2009, p. 263.
} 
Only in Chinese painting art, in the image thinking and perceptual cognition, this proposition is more able to highlight its original connotation. Ancient Chinese painting itself is to interpret the relationship between heaven and man. Through a series of morphological organization, it completes the dialogue between man and universe, man and god, and man and heart, and then sublimates and merges these ideas into infinite distance and chaos unity. It can be said that the idea of "unity of heaven and man" is the ontological aesthetic theory of early Chinese painting art.

Since it is a unity, there must be common ground between heaven, earth and people. In the early Chinese ancient painting concept, it mainly embodied in the following forms. First is the assimilation of the gods and men. Since the beginning of human emergence, the ancestors began to paint the human form through rock paintings and pottery, and to give these forms supernatural power. In the original witchcraft, people convey the image through the image and form of the self, and communicate the unknown world. The essence is to unite people with gods. "Animism" makes people regard heaven, earth and people as the carriers of gods. These "gods" above the object become the masters of all things in the spiritual world. There are gods, earth gods and people. Have a soul. The paintings of the characters before the Han Dynasty are embodied in the aesthetic concept of the assimilation of the gods, which means the gods of the heavens and the gods of the land. The idea is evident in the bronze statues of the Sanxingdui and the Warring States and Western Han Dynasty paintings. Due to the influence of ancient myths, legends, totems and sorcerers in China, people have combined gods and people in an illusory way to make mystics and reality one. ${ }^{4}$

Second, heaven and man have the same "qi". In the traditional Chinese philosophical aesthetics, people regard "qi" as the ontology of all things, which means all things are unified in "qi", and the heavens, the earth, and the people are all regarded as the result of "qi" gathering in different fields. The ontology of the early Chinese ancient paintings was also "qi", and the difference in the form of the characters was the difference in the "qi". Laozi said: "The Tao gives birth to one, one to two, two to three, and three to everything is negative and yang and they blow qi to be harmonious. It is pointed out that qi is the body of the universe. Wang Chong of the Eastern Han Dynasty put forward the "natural theory of vitality", pointing out that vitality is the body that constitutes the universe. In the Sixth Law, Xie He in the South Qi dynasty put forward the "vivid charm" and regarded the charm as the life subject of art, which have become the aesthetic core of ancient Chinese painting. "On the Tianshu, the weather is the main; under the Tianshu, the earth is the main; the gas is divided, the popularity is from it, and everything is according to it." 5 In Chinese art, the combination of human charm and cosmic temperament is the origin of "unity of heaven and man". This "qi theory"

Laozi, Li Cunshan tr., "Laozi Chapter 42", Zhongzhou Ancient Books Publishing House, 2008, p. 101.

Tian Daihua, "Huangdi Neijing, Su Wen· Six Micro-Principles", People's Military Medical Press, 2011, p. 251. naturally becomes the life subject in the "unity of heaven and man" proposition.

Third, the images of heaven and man are the same. The "image" in Chinese aesthetics is an abstraction of all things in the world. Like aesthetics, the "image" in painting is also the understanding and enlightenment realized by the painter. Therefore, the "images" in Chinese art are mostly embodied in the categories of "dao", "god", "qi", "virtual", "miao", "mysterious", etc., to reveal the law of life of "image". Because the things in Chinese painting are life-oriented and are constantly disguised, they are closely related to the universe of heaven and earth. Therefore, this kind of "image" in the life movement is the comprehensive value of the universe, which is the ontological attributes of art in Chinese painting. In the eyes of the Chinese, "the image of heaven and man" is a kind of value theory. Painting is the law of operation that combines the universe with the human form and carries all things. Therefore, heaven has the image of heaven, earth has the image of the earth, and human beings have human image. All the images change, emerge and convert. That is the unity of heaven and man.

Fourth, heaven and man are isomorphic. In traditional Chinese culture, people not only associate human's' "spirit", "qi", "image" with heaven, but also analogize the form, shape and composition of the human being and obtain the isomorphic thought of heaven is the man and man is heaven. This concept completely unblocks the difference between man and heaven, and regards "unity of heaven and man" as a law of conjunction. "The heaven is round while the earth is square, so the human's head is round and feet are square. There is sun and moon in the sky, and people have two eyes. There are nine continents on the earth, and people have nine orifices. There are wind and rain, and people have joy and anger. There is thunder and lightning in the sky while people have can make sound. There are four seasons in nature, and people have four limbs. There are five sounds in the sky, and people have five internal organs. There are six laws in the sky, and people have six hollow organs. There is winter and summer days, people can feel cold and heat. ${ }^{6}$ The isomorphic thoughts of heaven and man compare the figure to the heavens and the earth, and make the heavens and humans interpret and connect with each other in the same body. This concept has also become the source of value for the paintings of ancient Chinese characters, which means the figures in art must be separated from the appearance of itself, to undertake the universe, the big shape and the big image in the world, so that each shape and words carries the life and trajectory of the universe, and the perspective of the subject's god and heart. This kind of aesthetic thinking has become the cognitive ontology of the early Chinese characters painting, and it is also the source of thought in the value proposition of "unity of heaven and man".

\footnotetext{
Niu Bingzhan, editor-in-chief, "Huangdi Neijing Lingshu tr. and Evil", Traditional Chinese Medicine Publishing House, 2009, p. 410.
} 


\section{THE "INVISIBLE IMAGE" THEORY AND THE REPRESENTATION, THE IMAGE AND THE LAW IN THE EARLY ANCIENT PAINTINGS}

"The invisible image" comes from the forty-first chapter of Laozi's Tao Te Ching." The squarest thing doesn't have angle, while expensive artifacts are always finished lately. The greatest music has no sound while the biggest image has no image." Laozi makes an aesthetic interpretation of the natural object based on the highest realm of "Tao", which has become the aesthetic proposition of early Chinese painting art. The "big" that Laozi said is the ontological value of the cosmology. The "image" refers to the vital signs expressed by the concept of things. "Intangible" means free implication and is not bound. The original intention is that the most profound and authentic thoughts or realms in the universe are often not limited to the individual concepts of a certain thing, but are embodied in the temperament of the ideology and the movement of the body of life. In the early ancient paintings, the characters and scenes painted by the painters started from the mind, and the category of "images" was sublimated from the appearance to the "images." In the aesthetic path, it manifests itself as the "image" of the object to the "original image" universe, and then the "image" changes into a "legal image" that can move freely without shape. "'Therefore, there is no regular phenomenon that can surpass the heavens and the earth; there is no change beyond the four seasons." ${ }^{8}$ This biochemical process has become the general cognitive law formed by the early Chinese paintings in the category of "images".

The influence of "invisible image" on early painting art is mainly reflected in the following aspects: First, it solves the problems of "presentation" and "original image" of painting. Chinese painting art itself is the image and image generated in accordance with the values of Chinese aesthetics and the laws of the universe. This requires that the characters in the painting must move away from the objective and toward the aesthetic subjective world, from the image of the appearance to the image of thinking. In the ancient Chinese painting art, we need to use its appearance to determine its position, and then to fill the heart with the image of the universe and the laws of all things, so that the characters are united and integrated. Here, "representation" becomes the symbol of "this image" in the thousands of meteorology, is a cause point, and "this image" becomes the cosmic elephant contained and refracted by "representation", which is ontology. This is the basic relationship between the two. Because "original image" is a super "image", as well as a "legal image" and a "big image" that fits all things in the universe, it is impermanent, and has a shape with the charm, and it has no shape, so it is said "the big image is invisible". This epistemology constitutes the unique aesthetic path of early Chinese painting art.

Second, the influence of the "invisible image" on the art of painting is also reflected in the understanding of the origin

Laozi, Li Cunshan, tr, "Laozi Chapter 42", Zhongzhou Ancient Books Publishing House, 2008, p. 99.

Li Dingzuo, Chen Deshu, "The Collected Annotations of the Zhouyi · Xi Ci", Bashu publishing house, 1991, p. 287. of the "image". The "image" in the "invisible elephant" emphasizes the "legal image" of the universe, which means the ontology "dao" and "qi" of the image. This unblocks the relationship between "image" and "dao" and indicates "the origin of the image. The aesthetics of early Chinese painting in ancient times are consistent with the aesthetics of Taoism. They all take reflecting the "Tao" and "Qi" as the ultimate aesthetic. The depiction of their characters is only to realize the aesthetic process of transforming the consciousness of human beings from the appearance to the origin to highlight the care of the Tao. Therefore, the origin of the "image" is also the "dao" and "qi". Although it is depicting people, it has little connection with the object of human beings. This aesthetic way of looking at the object in the ontology has become the origin of the ancient Chinese painting art, and it has become the ontological value of the Chinese aesthetic concept.

\section{THE THEORY OF "Grasping MEANING AND ForgetTING IMAGE" AND THE ONTOLOGY OF "MEANING" IN ANCIENT EARLY PAINTINGS}

The Chinese classical aesthetic proposition is a series of constructs in growth. It is a cognitive system in which the Chinese continue to understand the universe and observe the heart with subjective and dialectical thinking. In Wei dynasty, the "grasping meaning and forgetting image" concept raised the relationship between "words", "images" and "ideas" to the category of aesthetic ontology, making "meaning" an independent aesthetic point. The "grasping meaning and forgetting image" inherit the definition of "image" in the "invisible image", which shifts the "image" from its visual form to the ontology of "meaning", thus generating "image", "artistic conception", "charm" and many other aesthetic concepts. Early Chinese ancient paintings were the practice forms of these values. They conveyed certain ideals and values and desires through the artist's understanding of the aesthetic meaning of the aesthetics, and finally realized the care for Tao. In essence, "grasping meaning and forgetting image" broke through people's understanding of the "image", and thus regarded the inexpressible "meaning" as the ontological manifestation of Tao, which also became the aesthetic spirit of ancient early painting.

"The image comes from the meaning." The words know image. The image can express the meaning best while words can express the image best. Words are born in the image, so you can find words to see the image; image is from meaning, so you can find the image to see meaning. The meaning is reflected by image, while image is expressed in words. Therefore, words can present image and when image is grasped, the words are forgotten; the image can maintain the meaning, so when people get the meaning, they forget the image." "Here, Wang Bi believes that "image" is a sign of all kinds of names. The ontology of "image" is "meaning" and "image" and "meaning" coexist. The purpose of "image" is to lead to the infiniteness of "meaning", and the obsession with "image" will be hidden in the "image" without knowing

\footnotetext{
9 Zhao Caihua, "General Knowledge of Guo Xue · Zhou Yi Lue·Ming Xiang”, Guangzhou Jinan University Press, 2011, p. 151.
} 
"meaning", which interrupts the aesthetic process from limited to infinite.

In the early Chinese ancient painting concept, "getting the meaning and forgetting the image" first solved the contradiction between "image" in the eyes and "meaning" in "image", and made people break through the understanding of the limited "image" and move toward the broader and farreaching realm of "image", which created the aesthetic category of "imagery." The Chinese paintings of the past all form a corresponding aesthetic order through a certain image expression, and finally clarify a certain value and philosophy in the picture, which is the aesthetic ontology of "Italian". This makes the "image" have the dual nature of ontology and the carrier, becoming an independent aesthetic unit.

The aesthetic realm of Chinese art is the psychological experience of feelings. It can't be said, because it will be said wrongly. As the materialized way of "Tao", "image" can't fully present the ontology of "Tao", but the "meaning" outside the image is the spirit and connotation of "Tao". This is why the aesthetic concept of Chinese painting art is always higher than its picture composition, or its picture form can never be parallel to human aesthetic thinking. For example, in Gu Kaizhi's "picture of Luoshen", there are numerous cars, horses and followers. People encounter the gods but separate with pity because of different ideal. The "images" of the appearances in the paintings are only very few, but in people's aesthetic thinking, in the ontological concept of "meaning", the ideal height of its construction is difficult to complete. This conception with the myth of sentiment and the aesthetic desire can only be understood in the "meaning".

Secondly, the influence of "grasping meaning and forgetting image" on the ancient concept of early painting is also reflected in its value, which means the perfection and infinity of "meaning". The so-called "image" has only become a way to "expressing meaning" in painting. People present the "image" to obtain the body of "meaning", and the mystery of "meaning" is outside the "image", which need people to comprehend the feelings. This is the "heart cosmology" that only Chinese art has. It also constitutes the ontological epistemology and methodology of ancient Chinese painting art, and becomes the core value of Chinese art aesthetic concept. Thirdly, the aesthetic proposition of "successful forgetting" has more clearly defined the aesthetic desire and aesthetic ideal of Chinese painting. The purpose of the image in painting is not the aesthetics of the picture, but the more ideological revelation and life thinking through the picture. Although the characters in the painting are from the image or mental imagery of the painter, they are just a symbol of concept. People's aesthetic desire and aesthetic purpose are to go to the farther space through the ladder of "image" to realize the perfection of thinking and harmony in cognition. This is also the ontological value of this proposition in the art of painting.

\section{CONCLUSION}

As the origin rule of Chinese aesthetic consciousness, the aesthetic proposition guides the biochemical evolution of all things, and organizes the operating laws of all kinds of
Vientiane, carrying the ancient civilization of China to move forward. Ancient Chinese painting art draws on these epistemology and methodology, and uses the carrier of formal image to explain these concepts and consciousness, and constructs the most original aesthetic purpose of Chinese art.

The ancient Chinese early painting concept and the aesthetic proposition have intrinsic unity. They are the ontological understandings generated by the ancients on the basis of cosmology and concept theory as well as the wisdom and fruit that people have realized in the aesthetic speculation in a certain period. These theories are not only the common understanding and value dependence of the social subject, but also the spirituality and spiritual conversion of the aesthetic concept of the painting art. For thousands of years, it has continuously formed an ontological construction in the epistemology and methodology of Chinese art, cleared all the ideological shackles for people, and has guided people's mental thinking to the source. Until today, this aesthetic cognition, aesthetic consciousness and logic are still the soul of Chinese painting aesthetics.

\section{REFERENCES}

[1] Hao Yong, "The Gene of Chinese Culture: Confucianism and Taoism", Guangming Daily Press, 2009, p. 83.

[2] Dong Zhongshu, Zeng Zhenyu, "Chun Qiu Fan Lu, Yin and Yang Yi", Henan University Press, 2009, p. 297.

[3] Dong Zhongshu, Zeng Zhenyu notes, "Chun Qiu Fan Lu, Deep Inspection", Henan University Press, 2009, p. 263.

[4] Laozi, Li Cunshan tr., "Laozi Chapter 42", Zhongzhou Ancient Books Publishing House, 2008, p. 101.

[5] Tian Daihua, "Huangdi Neijing, Su Wen- Six Micro-Principles", People's Military Medical Press, 2011, p. 251.

[6] Niu Bingzhan, editor-in-chief, "Huangdi Neijing Lingshu tr. and Evil", Traditional Chinese Medicine Publishing House, 2009, p. 410.

[7] Laozi, Li Cunshan, tr, "Laozi Chapter 42", Zhongzhou Ancient Books Publishing House, 2008, p. 99.

[8] Li Dingzuo, Chen Deshu, "The Collected Annotations of the Zhouyi · Xi Ci", Bashu publishing house, 1991, p. 287.

[9] Zhao Caihua, "General Knowledge of Guo Xue· Zhou Yi Lue·Ming Xiang”, Guangzhou Jinan University Press, 2011, p. 151. 